\title{
The interaction of deprivation and delay of reinforcement under a fixed-ratio schedule of responding
}

\author{
LARRY D. HILGERT and GARY F. MEUNIER \\ Ball State University, Muncie, Indiana 47306
}

\begin{abstract}
Interaction of deprivation and delay of reinforcement was studied in an operant framework in this experiment. Four male Sprague-Dawley rats at approximately 250 days of age served as subjects. They were exposed to a series of conditions within a counterbalanced design. The four conditions represented the orthogonal combinations of amount of delay $(0$ and $10 \mathrm{sec})$ and levels of deprivation $(75 \%$ and $85 \%)$. Conclusions from the study concerned the finding that the effect of a delay in reinforcement is magnified by an increase in deprivation and the value of searching for such interactive effects in operant research.
\end{abstract}

Delay of reinforcement has a long history of experimentation with a great variety of apparatus. Most studies have found that an increase in delay is followed by a decrease in performance. Recent research in the operant framework, however, has indicated the specificity of the effects of the delay procedure. For example, Morgan (1972) found that, in the case of fixed-ratio schedules, as the delay in reinforcement increased so did the pause after the reinforcement and before the organism begins responding for the next reinforcer (the postreinforcement pause).

The effects of delay of reinforcement have also been found to interact with other variables. The relationships between sucrose concentration (McCloskey \& Tombaugh, 1971), reward magnitude (Shanab, Rouse, \& Cavallaro, 1973), secondary and partial reinforcement (Tombaugh, 1973), and contingency descriptions using fixed-ratio schedules (Frazier, 1973) have all been studied in recent experiments. The purpose of the present experiment is to search for an interaction between delay of reinforcement and level of deprivation. Although the effects of each have been thoroughly documented, their interactive effects in the operant setting have not been reported.

\section{METHOD}

\section{Subjects}

Ten naive male albino rats of Sprague-Dawley stock were obtained from Harlan, Inc., Cumberland, Indiana, at approximately 100 days of age, and served as subjects. The rats were fed ad lib for 150 days, after which time six of the rats were allowed to continue ad lib and the other four rats were deprived to $80 \%$ of their weight. Deprived weights were adjusted according to the weight gain of the six rats that were fed ad lib throughout the experiment (Capaldi, 1972).

This experiment is based on a portion of a thesis submitted by Larry $D$. Hilgert in partial fulfillment of the requirements of a masters degree at Ball State University. The study was partially supported by a grant to Gary F. Meunier by the Ball State University Office of Research.

\section{Apparatus}

The test cage was a LVE Model 142-28 in a sound-attenuated chamber programmed by standard relay-type equipment located in an adjacent room. Reinforcers consisted of Noyes $45-\mathrm{mg}$ food pellets. A supply of water was maintained in the home cage.

\section{Procedure}

The four experimental rats were shaped to leverpress in the test cage and then placed on a schedule of continuous reinforcement for one session (100 reinforcers). The schedule was then gradually increased to a fixed ratio 40 (FR 40) and was maintained at that level throughout the experiment. Each animal's performance was stabilized at least twice at each of the four treatment combinations produced by the two levels of deprivation $(75 \%$ and $85 \%$ of ad lib) and delay $(0$ and $10 \mathrm{sec})$ with a reversal type of design. Stability was described in terms of a baseline definition of no upward or downward trends in postreinforcement pause and rate of response for a period of 8 days. In order to control for possible sequence effects, the schedule of presentation of conditions was different for each rat. ${ }^{1}$ Presence of the delay was signaled by a tone which sounded continuously throughout the 10 -sec interval $(12,000 \mathrm{~Hz}$ at $85 \mathrm{~dB})$. Presence of the 0 -sec delay condition was signaled by a 40-msec tone that accompanied delivery of the reinforcer. Although the lever remained in the chamber at all times, responses made during the delay did not effect the scheduled contingencies. Finally, an experimental session lasted until the rats received 100 reinforcers and sessions were conducted daily.

\section{RESULTS}

Three different dependent variables, the postreinforcement pause, responding rate, and responding during the delay, were measured and will be discussed in turn.

The postreinforcement pause (PRP) was defined as that interval between the delivery of the $\mathrm{n}^{\text {th }}$ reinforcer and the first response before the $n+1$ reinforcer. A graphical summary of these data is presented as Figure 1, where mean session PRP (in seconds) is plotted for each rat as a function of deprivation and delay level. As is obvious from this figure, PRP increased with increases in delay and decreases in 


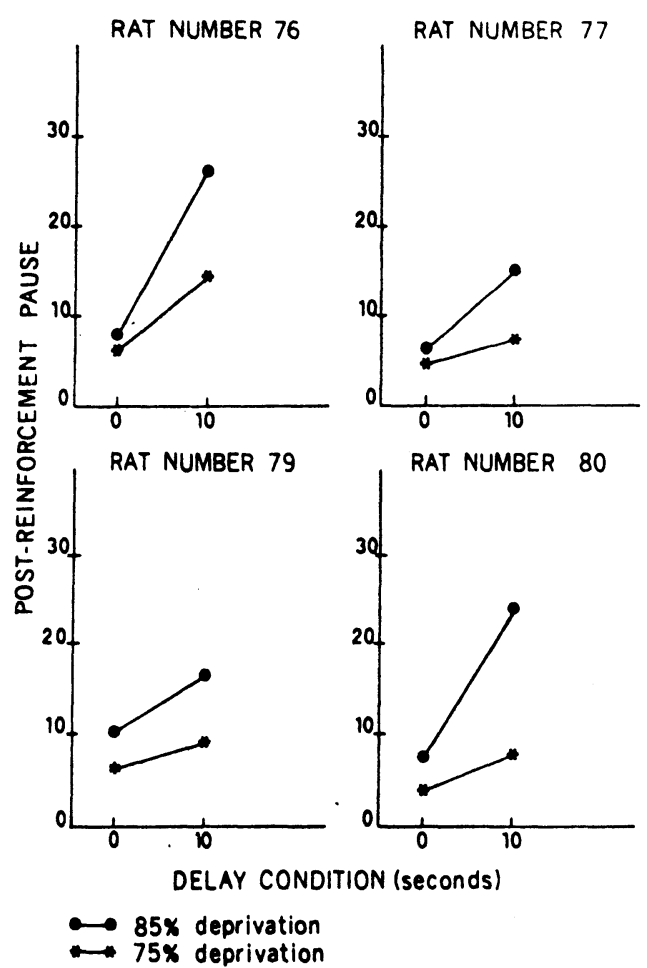

Figure 1. A graphical representation of average postreinforcement pause for each rat under four experimental conditions.

deprivation. Additionally, an interaction occurred in all four sets of data; the difference between performance at the two levels of deprivation was greater at the $10-\mathrm{sec}$ delay than at the 0 -sec delay condition.

Response rate, the second dependent variable, was measured as the interval which commenced with the first response after the PRP and terminated with the delay tone. These data are presented as Figure 2, where the mean rate of responding (per minute) is plotted for each rat as a function of deprivation and delay conditions. As is obvious from the figure, with the exception of Rat 77 at the $75 \%$ deprivation level, increasing the delay produced decreases in responding rate. The data also indicate that for three of the rats differences due to deprivation levels will be larger with a 10-sec delay than a 0 -sec delay. Due to the failure of Rat 80 to replicate this interactive effect, however, and the unusual performance of Rat 77 at the $75 \%$ deprivation level, the data may best be considered suggestive rather than definitive on this point.

Finally, the third dependent variable, responding during the delay, was measured as the number of responses occurring during the 10 -sec delay period. (For obvious reasons, records were not kept of responding during the $0-\mathrm{sec}$ delay.) These data are presented as Table 1 , where the mean cumulative responses during a session are shown as a function of level of deprivation for each animal. With the exception of Rat 79, they

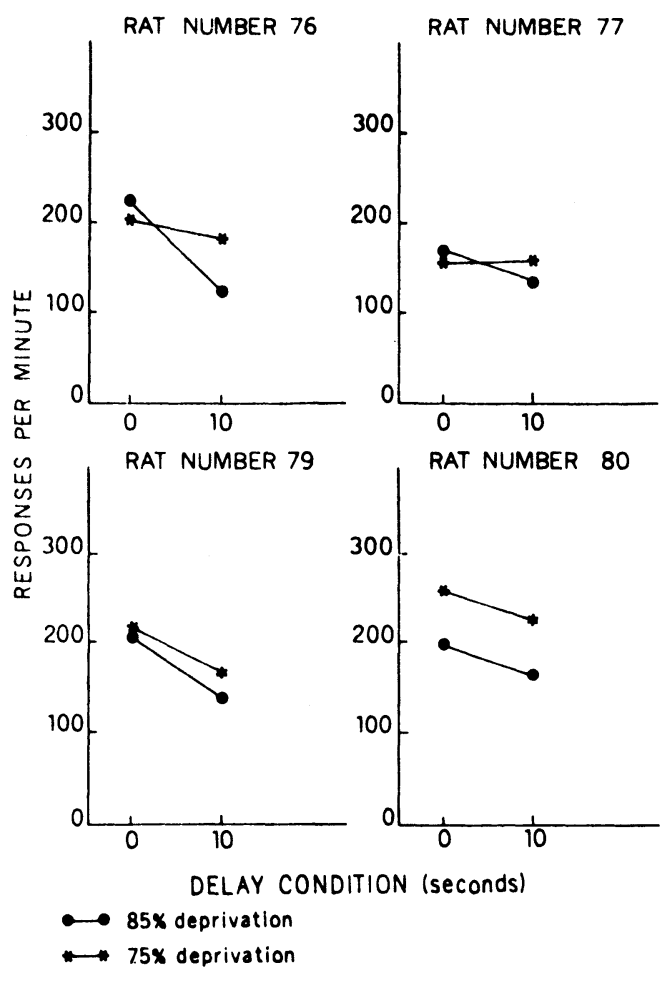

Figure 2. A graphical representation of average response rates for each rat under the four experimental conditions.

typically follow the pattern of increased deprivation leading to increased responding. Although the actual amount of this responding varied across trials within a session, the total amount was quite consistent across sessions. Representative cumulative records from two of the animals (Rat 76 and Rat 79 ) are presented as Figure 3 to demonstrate that the delay periods were adequately discriminated. The letter " $\mathrm{C}$ " in this figure indicates particularly good examples of this discrimination.

\section{DISCUSSION}

Demonstrating that the postreinforcement pause (PRP) is sensitive to changes in various independent variables is not difficult. For example, Morgan (1972) found an increase in PRP with additional delay before reinforcement, and Sidman and Stebbins (1954) reported that PRP decreased as the level of deprivation increased. The unique finding from the present

Table 1

Cumulative Responses During the Delay Period for an Average Session

\begin{tabular}{ccc}
\hline & \multicolumn{2}{c}{ Deprivation Level } \\
Rat & $75 \%$ & $85 \%$ \\
\hline 76 & 2452 & 1104 \\
77 & 2404 & 1361 \\
79 & 2557 & 2728 \\
80 & 2893 & 1839 \\
\hline
\end{tabular}




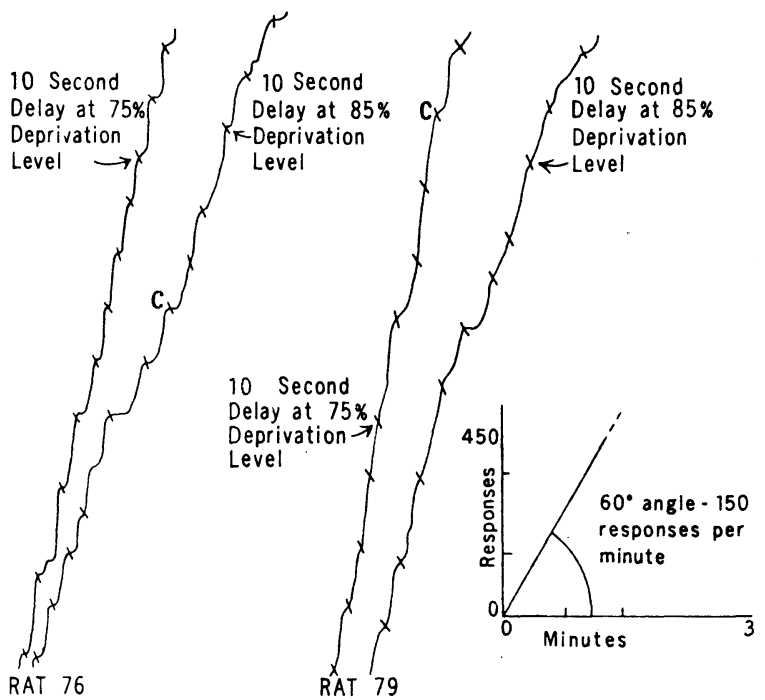

Figure 3. Cumulative records for Rat 76 and Rat 79 ("C" showing discrimination of the delay).

experiment, therefore, involves the interaction effects of these two variables on the PRP, i.e., in this study the effects of deprivation were magnified by the addition of a delay before reinforcement. The presence of this interaction suggests the usefulness of studying more than one variable concurrently in the search for functional relationships and the worth of this notion is also supported by the rate of responding data. Although not conclusive, these data are certainly suggestive of the same interaction found with the PRP data.

Finally, mention should be made of an alternative explanation of this interaction. This alternative hinges on the facts that (a) the actual amount of responding during the $75 \%$ deprivation level was often twice as large as that during the delay under $85 \%$ deprivation, and (b) at higher levels of deprivation discrimination often is not accurate (Powell, 1973). It may be reasonable to argue, therefore, that due to the animals' failure to discriminate the delay, differences in PRP and response rate could have been caused by a simple increase in the number of responses emitted before reinforcement in the $75 \%$ condition (Felton \& Lyon, 1966). Although it is difficult to completely rule out this possibility, certain arguments can be made against it. For example, perusal of the cumulative records (see Figure 3) does indicate that some discrimination was occurring, and previous experiments (Meunier \& Ryman, 1974; Pierce, Hanford, \& Zimmerman, 1972) have indicated an invariance of results across different types of delay procedures. Finally, the differences in PRP for Rat 79 parallel those differences observed for the other animals, although he responded equally during the delay regardless of deprivation level.

\section{REFERENCES}

CAPaldi, E. D. Effect of rats' straight alley performance of shifts in body weight as a function of method of weight maintenance. Psychonomic Science, 1972, 28, 44-46.

Felton, M., \& Lyon, D. O. The post-reinforcement pause. Journal of the Experimental Analysis of Behavior, 1966, 9, 131-134.

Frazier, F. R. Fixed ratio schedule responding as a function of contingency descriptions and reinforcement delay. Psychological Reports, 1973, 33, 667-672.

McCloskey, J. L., \& Tombaugh, T. M. Sucrose concentration, constant delay of reward, and resistance to extinction. Journal of the Experimental Analysis of Behavior, 1971, 88, 128-132.

Meunier, G. F., \& Ryman, F. Delay of reinforcement in fixed-ratio behavior. Psychological Reports, 1974, 34, 350.

Morgan, M. F. Fixed ratio responding under conditions of delayed reinforcement. Journal of the Experimental Analysis of Behavior, 1972, 17, 95-98.

Pierce, C. H., Hanford, P. V., \& Zimmerman, J. Effects of different delay of reinforcement procedures on variableinterval responding. Journal of the Experimental Analysis of Behavior, 1972, 18, 141-146.

Powell, R. W. Effects of stimulus control and deprivation upon discriminative responding. Journal of the Experimental Analysis of Behavior, 1973, 19, 351-360.

Shanab, M. E., Rouse, L. O., \& Cavallaro, G. Effects of shifts in delay of reward as a function of reward magnitude. Journal of General Psychology, 1973, 89, 59-66.

Sidman, M., \& Stebins, W. C. Satiation effects under fixed-ratio schedules of reinforcement. Journal of Comparative and Physiological Psychology, 1954, 47, 114-116.

Tombaugh, T. N. An evaluation of secondary reinforcement effects in a comparison of partial reinforcement and partial delay of reinforcement. Canadian Journal of Psychology, 1973, 27, 70-76.

\section{NOTE}

1. A tabular representation of the design is available upon request.

(Received for publication September 2, 1975.) 